\title{
AN EXAMINATION OF THE SUITABILITY OF A UK PFI MODEL WITHIN THE CZECH REPUBLIC, THE REPUBLIC OF IRELAND, PALESTINE (GAZA-WEST BANK), PORTUGAL AND TURKEY.
}

\author{
Dr David Eaton ${ }^{1}$, Rifat Akbiyikli ${ }^{1}$, Dr Teresa de Lemos, ${ }^{2}$ Louis Gunnigan ${ }^{3}$, \\ Dr Rana Ozen Kutanis ${ }^{4}$, Martin Casensky ${ }^{5}$, Josef Ladra ${ }^{5}$, Nabil EI \\ Sawalhi ${ }^{6}$
}

BuHu (Built \& Human Environment) Research Institute, University of Salford. UK. ${ }^{1}$, IST Lisbon, Portugal $^{2}$, Dublin Institute of Technology ${ }^{3}$, Sakarya University, Adapazari, Turkey ${ }^{4}$, CVUT Prague, Czech Republic ${ }^{5}$, UNRWA-Gaza Strip ${ }^{6}$.

\begin{abstract}
The objective of this research was to identify the cross-cultural similarities and differences of the implementation of the UK PFI procurement process in different contexts. The research methodology adopted was the SLEEPT approach, the identified features (Social, Legal, Economic, Environmental, Political, Technological) are examined from source material of various projects within the stated nations. A Delphic approach of confirmation by national collaborators from each country $\dot{s}$ utilised. Confirming and disaffirming features are examined utilising exogenous cultural drivers.
\end{abstract}

The conclusion of this research identifies cross-cultural features of six different cultures presented as a 'cultural compass' which will inform the development of future PFI/PPP projects.

\begin{abstract}
The impact of this research will have implications for the appreciation of cultural similarities and differences of national 'construction cultures' for effective project delivery of future PFI/PPP projects. PFI projects should be considered within the existing exogenous features of a nation. Merely implementing standardised PFI protocols without recognising these inherent differences will lead to project failures. This paper offers an approach that can be generalised for adoption by nations considering the introduction of PFI as a procurement process.
\end{abstract}

Key Words: PFI; PPP; Cross-cultural study.

\section{INTRODUCTION}

There is always confusion about PPP (Public Private Partnership) and PFI (Private Finance Initiative). PFI is a Pub lic Service delivery type of PPP where responsibility for providing public services like transportation, sanitation, etc is transferred from the public to the private sector for a considerable period of time. (Akintoye et al., 2001). The PFI is therefore a generic classifier for all types of 'construction PPP'. "The whole concept of [PFI] is a government policy to tackle financial problems in facility provision and integrate private management skills to increase efficiency, effectiveness and quality" (HM Treasury, 2000). PFI is therefore based upon a financial premise that was introduced by the UK Government in 1992. For a detailed introduction to the principles and concepts of PFI the reader is referred to previous work. For example, Akintoye et al, (2001), Eaton \& Akbiyikli, (2005). The PFI has become an important part of UK Government's infrastructure investment programme with projects currently being signed at a rate of $£ 3-4$ billion per annum (Henderson Global Investors, 2003). The use of a PFI model is not 
restricted to the UK and it is increasingly being utilised across the world in countries such as Japan, Denmark, Canada, Australia, Greece, Portugal and South Africa. (Eaton \& Akbiyikli, 2005,)

The launch of PFI in the UK marked a dramatic shift from the general presumption against the use of private finance in social infrastructure projects which had previously existed in the UK (Hall, 1998). Private infrastructure financing is the fastest growing method of financing the construction of assets needed for public services. In the short-term, PFI projects shift more risk onto construction firms (private sector), but over the longer-term, PFI funding can help to reduce the impact of economic cycles by providing more stable cashflows during the long concession period.

The objective of this paper is to examine the suitability of this UK model for implementation into other nations. The premise of this paper being that the UK model is isomorphic with the national characteristics of the UK, and consequently its construction industry 'drivers' and therefore it is an effective model in the UK.

These national characteristics are loosely classified as national 'culture' and therefore the PPP system will be affected by, and will affect, such cultural issues. It is not intended to

The effectiveness of the UK model therefore cannot be guaranteed under conditions of differing national cultures. Therefore the question to be answered for other nations is to what degree is this UK model isomorphic with their own particular national characteristics. The corollary is therefore what changes are likely to be required to the UK model to achieve greater compatibility with particular nation's national characteristics.

\section{THEORETICAL IMPERATIVES OF PFI}

The derivation of the concepts, drivers and characteristics of PFI is defined in Eaton \& Akbiyikli (2005).

A brief synoptic review is presented below:

\section{Key concepts of PFI:}

- Governments purchase services not assets;

- Seek Value for Money for the Government Authority;

- Provide extensive Governmental Risk Transfer and improved Risk Management;

- Incorporate private sector know-how and expertise;

- Increase the incorporation of Innovation;

- Provide Whole life-cycle costing for the entire Project life-cycle.

\section{Key drivers of PFI:}

- A national need for better facilities and infrastructure;

- Increasing demand for public sector services;

- Governmental search for efficiency and creativity; 
- A search for Innovation

- Governmental Financial necessity; and

- Desire to introduce competition in traditional Government services.

\section{Key PFI characteristics:}

- Capital investment from Private Sector;

- Output specification for Services;

- Defined Operation and Service content;

- Charges for defined quality of Service availability;

- Risk transfer to the managing party best able to control the specific risk.

\section{Key enablers of PFI (SLEEPT):}

- Social - Public acceptance of private sector involvement

- Legal framework - standardised documentation;

- Economic - Access to significant Private Sector Borrowing;

- Environmental - Clearly defined Sustainability and Impact criteria;

- Political framework - International, National and Local will or commitment;

- Technological - Access and availability of Quality PFI practitioners and experienced project sponsors.

In PFI procurement the public sector defines what the services will be and the private sector determines how those services will be provided. This form of procurement gives more certainty of the end product since its solution lies in an output oriented approach. This means that the public sector establishes the result it wishes to have and the parameters and constraints within which those results are to be delivered, but within those parameters and constraints it leaves it to the private sector partners to determine the best way of achieving those results. According to Akbiyikli and Eaton (2004) the PFl's philosophy is: 'A government policy to tackle financial problems in service provision and to integrate management skills to increase efficiency, effectiveness and quality and to exploit new opportunities.' Therefore because of the increasing globalisation of PFI/PPP as a procurement philosophy, the appreciation of the cultural differences between nations will assist in minimising the potential difficulties of applying PFI within differing cultural and social 'systems'

\section{CROSS-CULTURAL METHODOLOGY}

This study is an initial developmental study. It aims to identify the key features in each of the national environments so that necessary and sufficient consideration can be given at the initial concept phase of a PFI to attempt to minimise the intra-cultural conflict. This intra-cultural conflict would manifest itself in inconsistencies between the UK model of PFI and the host nation. For example, a UK model assumes that PFI construction can be provided by a national/international main contractor. Therefore applying this concept to a nation that does not have indigenous national main contractors is creating a potential intra-cultural inconsistency within the UK PPP model. This work is 
intended to identify these potential inconsistencies before conception in order that amelioration can be effected. The inconsistencies may cause difficulties for the PPP in terms of the structures, systems, strategies or behaviours of the people, required in the implementation of the PPP project. This paper does not propose changes to the UK model for particular national applications. This will form the substance of a future paper.

A holistic and hence generalised cultural perspective is presented based upon a 'cultural compass' approach (Lessem \& Neubauer, 1994). The concepts of opposing linear scales; for example the Masculinity-Femininity and High Power Distance Index (PDI) - Low PDI (Hofstede, 1980) and multi function attributes (Hampden Turner \& Trompenaars, 1993) have informed the creation of the cardinal compass points. The authors have not identified any work that specifically identifies the cultural characteristics of PFI/PPP for national comparisons.

However, the cardinal points have been created specifically to represent the SLEEPT, Social, Legal, Economic, Environmental and Political features specific to PFI. These cardinal points have been reviewed by a quasi-Delphic approach by numerous contributors to the research. The original cardinal points where developed over a period of six years. They were derived from analysis of 25 detailed PFI case studies. The cardinal points were presented to panels of contributors from the different collaborating nations for debate. In February 2005 the proposed cardinal points were presented to an international audience at a CIB conference. (Eaton et al, 2005). Feedback from this presentation was incorporated into the final cardinal points as presented. Other national working panels subsequently cooperated in evaluating the cardinal points and adding other nations to the 'cultural compass'.

The proposed specific features have the potential to be further developed, however for the purposes of this research they provide an adequate representation of the distinctive characteristics of the national cultures for application within the PPP model.

An initial examination of the summary data presented in Figure 1 indicated how unrepresentative a UK approach was for the sample countries. The vertical scale indicates the number of degree points (clockwise) away from the UK's position a nation is for a particular characteristic. Figure 1 indicates the variance from the UK position for the examined features of PFI for the other countries of the study. This suggests many potential intra-cultural inconsistencies when the UK model of PFI is introduced. 


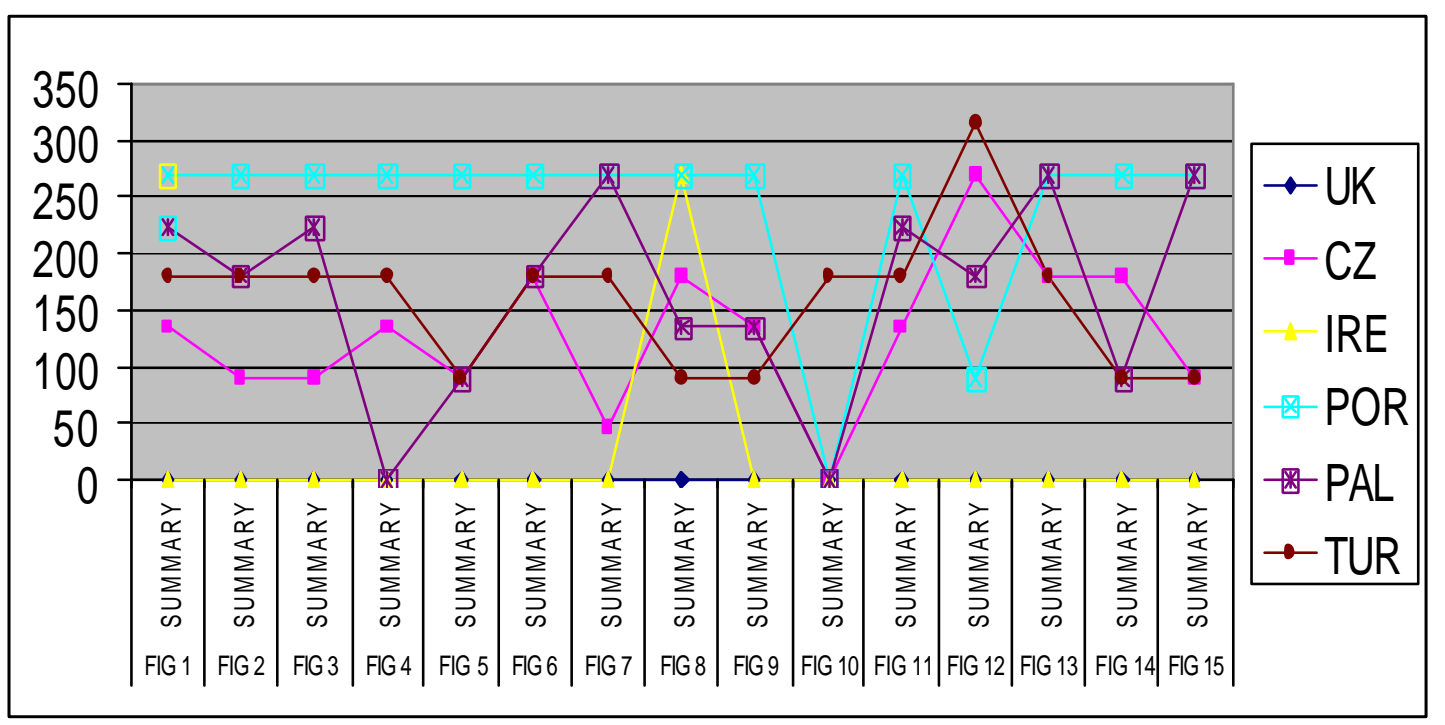

Figure 1 Cross Cultural Comparison with the UK.

There was some suggestion within the data that a more regionalised approach could be achieved. Taking Portugal as an example, many of the components lie on the $y$ axis at scale point 265. This indicates a position for Portugal away from the UK position. There is still variance from this control, but the variance is greatly reduced from that of comparing with the UK position. The other nations indicate other control positions around the compass. A method of representing these national 'generalised positions' and the consequential ability of identifying the individual national and component variances from this 'generalised position was needed.

The cardinal points as created have as a definition of 'cardinality' placed the UK as the Western cardinal point for all features. This essentially means that there is zero variance of the United Kingdom to the application of PFI within the UK. As a consequence this would mean that if the UK model was 'ideally suited' for introduction in another country, that country would show the same cultural 'profile' as the UK. That is a horizontal line on the 0 scale of the $y$ axis, and no variance. Figure 1 showed that this was not the case.

For the purposes of the 'cultural compass' the UK will always be the West point of the assessment. This introduces the assumption that there is no variance between the UK application of PFI and its utilisation within the UK. The authors recognise this as an assumption. However the premise is that there is no theoretical inconsistency in the application of PFI within the UK. The difficulties are practical post-hoc difficulties. This study is not intended to identify these post-hoc difficulties. It is to be used to ameliorate the conceptual and pre-inception inconsistencies. There is an indication from the analysis of Figure 1 that the other countries will have a control location, but that for specific features the location can be altered.

Therefore the starting premise within this paper, as indicated by Figure 1, and confirmed by the Delphic approach, is that 'generally': 
Ireland will also be 'West' - having a control position at 0 on the $y$ axis;

Turkey will be 'East' - having a control position at 180 on the $y$ axis;

Portugal will be 'South' - having a control position at 270 on the $y$ axis;

The Czech Republic will be located as 'North-East' since it has feature that are considered to be combinations of both the generic 'North' and 'East' groups - indicated by 135 on the y axis;

Palestine will similarly be located as 'South-East' - having a generalised position at 225 on the $y$ axis.

This demonstrates the flexibility provided by the 'cultural compass' model as presented within Figure 2 as it covers the six sample nations. Two members of the 'West' control grouping, one member of the 'East' control grouping and one member of the 'South' control grouping. It has not been possible to collate and correlate a 'Northern' member within this paper. Members of sub-groups (North-East \& South-East) are also represented.

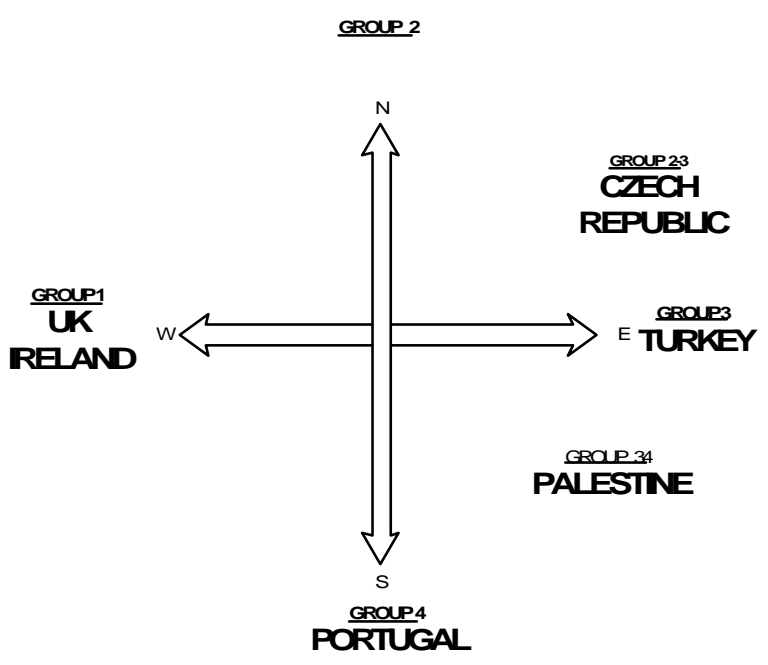

Fig. 2 Generalised Cultural Compass with Control Positions

The control position on the cultural compass indicates a presumed preference to a particular style of PFI, ie, a Western style PFI model, a Northern style PFI, etc. A cardinal points approach has been introduced. This introduces 8 alternative control models as variants of PFI. Even with this approach significant variation still existed within the model. Detailed disaggregation of the cultural components has therefore been undertaken. The 'national' control location for each parameter (component of PFI) has been determined by agreement of the 'local' experts via a 'Delphic' approach. 
This 'control position' is then analysed for each nation by a series of component-by-component disaggregation. This indicates the compatibility of the control position for a particular feature. For example, how compatible the Eastern model is for Palestine when examining the features of the Palestinian legal system.

A SLEEPT methodology (Social, Legal, Economic, Environmental, Political, Technological) analytical approach is utilised within this research for the analysis of components. The SLEEPT mnemonic has been created by CRMR: The Centre for Risk Management Research at the University of Salford as a tool for separately identifying 'drivers' of a process or object. It is based on the segregation of activity into six component parts both endogenous and exogenous of the unit of appraisal. No attempt is made to analyse the quantum of interdependency and co-dependency of the SLEEPT components. The 'local' experts identify the control position on the compass for each individual component incorporating a holistic qualitative composite of the other five components.

These individual component positions are then compared with the pre-defined national control position. This gives a 'component-by-component' profile of variability, and hence the applicability of a 'national model' of PFI.

The variations in compatibility are demonstrated by movements away from the control position. Using the current UK PFI model as the control Western PFI model, then the UK and Ireland are analysed. The UK shows no variation from the generalised position as would be expected. The other nations are similarly compared against their own pre-defined cardinal control location.

This holistic integrative perspective has been adopted throughout the crosscultural examination of PFI/PPP as presented below.

\section{COMPONENT -BY-COMPONENT POSITIONS}

\section{SOCIAL}

The social and cultural 'norms' within a nation can significantly alter the behaviours of people. They will also affect the operation of systems and structures. Consequently the strategies that are put in place to achieve effective and efficient operations should be tailored to the individual national 'social norms'. The first aspect examined in Fig.3 is the generalised cultural philosophy. The UK and Ireland are classified as 'pragmatic', the Czech Republic is 'rational', Portugal is 'humanistic' and Palestine and Turkey are 'holistic'. Fig.4 then develops a philosophical situational response to 'problem solving. In this the UK and Ireland are once again co-located as 'action' orientated - a get it done quickly, experimental approach. The Portuguese approach is again based upon a humanistic approach and is related to a 'Feeling' or emotional response. The Turkish response is more 'reflective' and considered. The Palestinian approach is seen as a combination of 'Reflection and Feeling'. The Czech approach is classical reflection and deep 'thought' before implementation. 


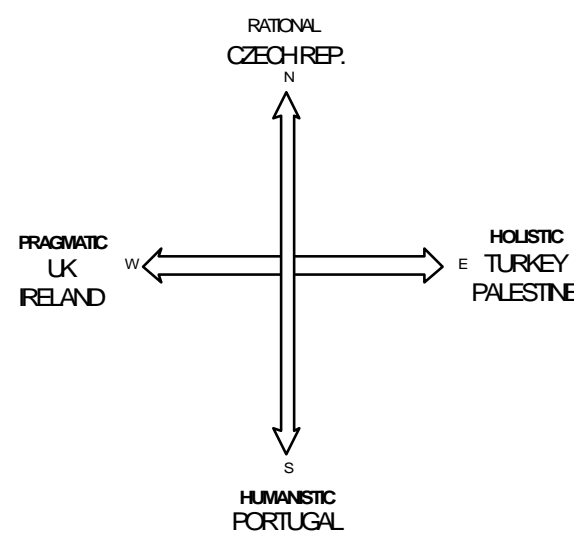

Fig. 3 Philosophical Perspective

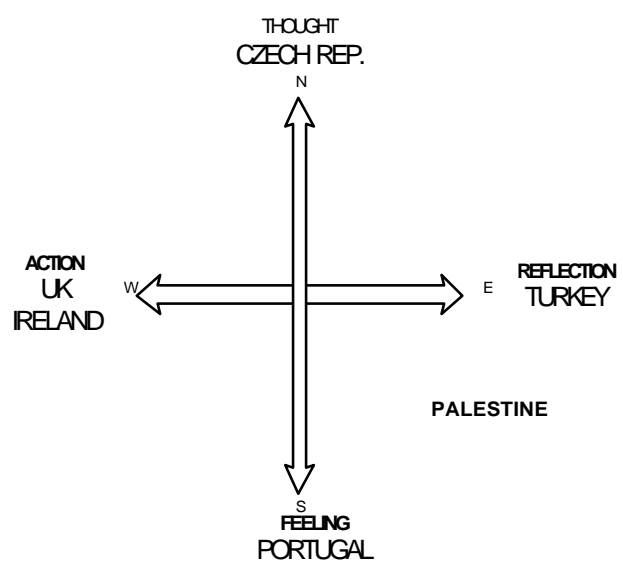

Fig.4 Philosophical Situation Response

\section{LEGAL}

The national legal systems have a significant impact on the cultural responses to construction activity. The original PFI philosophy has originated within the UK common law legal system. Translating that common law approach to other legal systems has inherent difficulties. In some nations issues that would appear to be pre-determined can unravel as disputes move away from site and into the courts. Fig.5 presents a synoptic review of the prevalent legal philosophy.

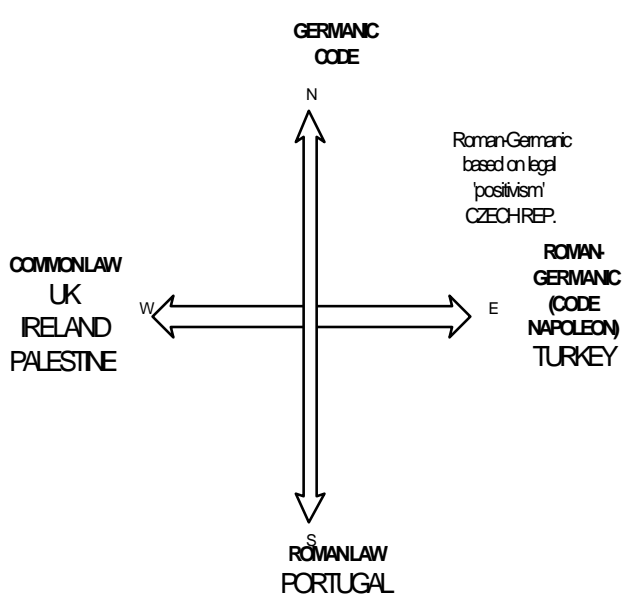

Fig. 5 Legal System

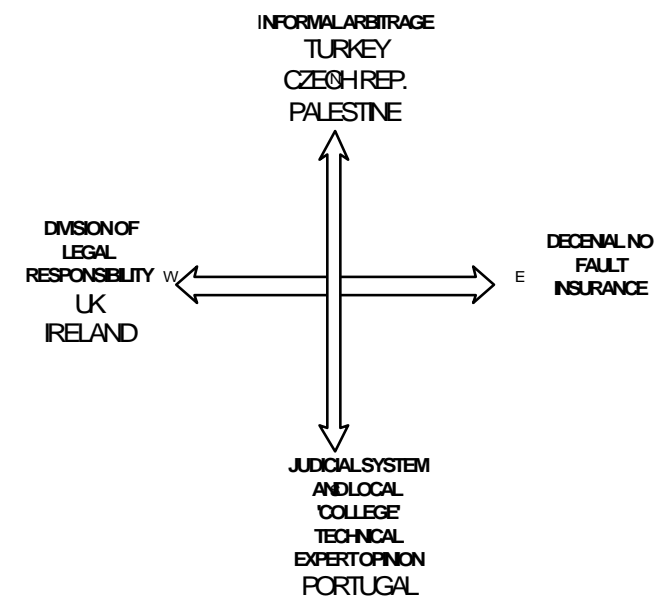

Fig. 6 Construction Dispute System

A further legal difficulty within PFI is the requirement for the settlement of contractual disputes. The legal responsibility of the parties alters on a national basis. Fig.6 identifies the typical approach to dispute resolution. The UK and Ireland has a strict legal liability approach. In Portugal disputes are referred to the local 'college' for resolution, whilst in Turkey, Palestine and the Czech Republic the approach is based upon informal negotiation or 'arbitrage'.

A further significant difference in the national legal approaches is the consideration of the intended longevity of relationships. In the UK the approach is that each PFI contract should be treated independently as a one- 
off agreement. In Ireland there is more consideration of the longer term effect of continued development together (a form of partnering expectation) beyond a single PFI project. In Portugal there is a tendency towards individual personal relationships, hence the continuance of individual personal relationships is more significant than continued contractual linkages. Hence continuance of 'friendly' relations between particular senior individuals is more significant than the strict legal relationship. Turkey, Palestine and the Czech Republic have a combination of the individualistic approach of Portugal and the Partnering approach of Ireland.

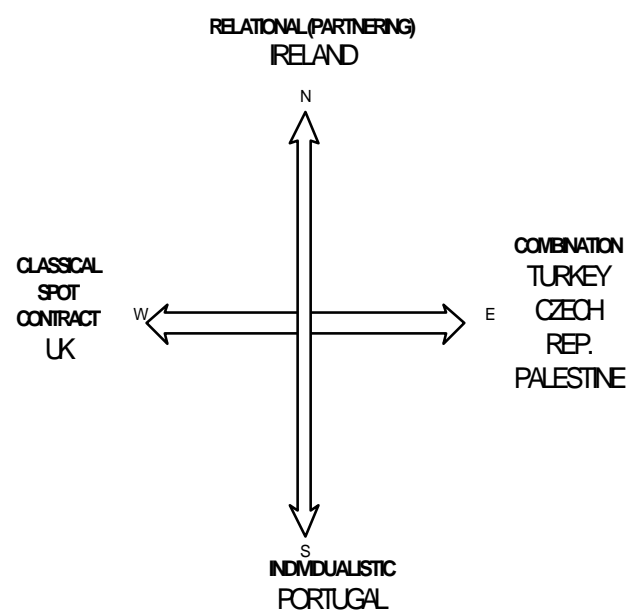

Fig. 7 Construction Contract

\section{ECONOMIC}

The management style (Fig. 8) as applied to UK and Ireland PFI projects is 'commercially' oriented. The projects are commercial self-contained cost centres. The typical SPV (Special Purpose Vehicle - concession holder) may place the construction and operational contracts with subsidiaries of the same Company group. However they will treat the subsidiary in exactly the same way that they would treat any other contractor. The Portuguese and Palestinian approach would be to consider the implications for the whole group or 'family' of companies. The Turkish approach would be a recognised 'Bureaucratic' approach. The Czech approach is a combination of Industrial and Commercial.

Figures 9, 10 and 11 identify other differing aspects of the economic application of cultural diversity within PFI projects; namely business orientation, process and competition basis. 


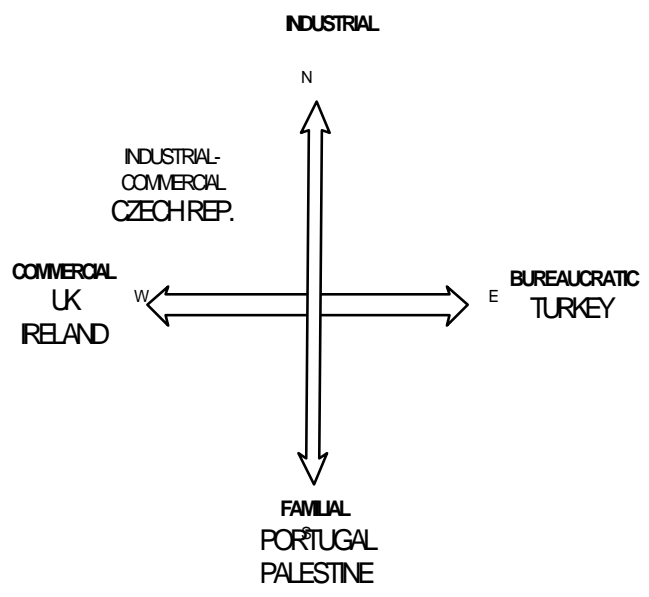

Fig. 8 Management Style

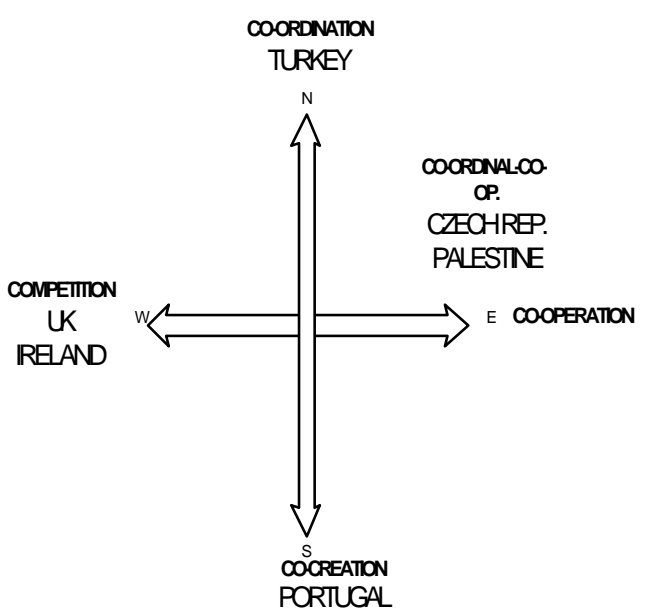

Fig. 10 Business Process

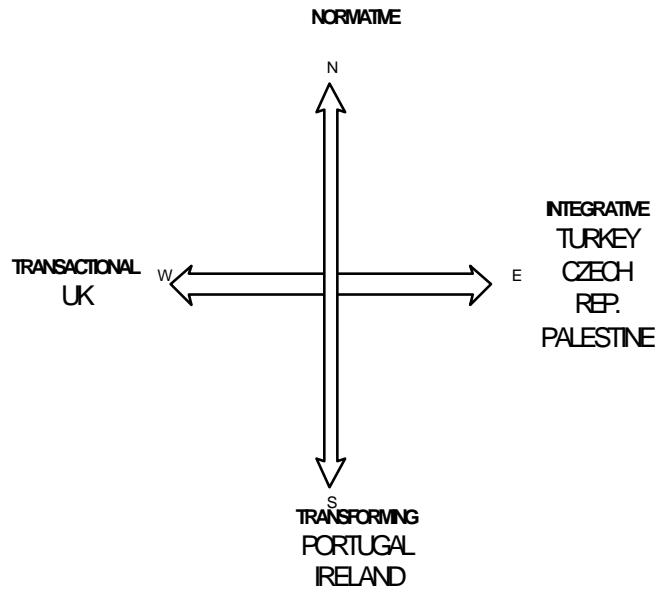

Fig. 9 Business Orientation

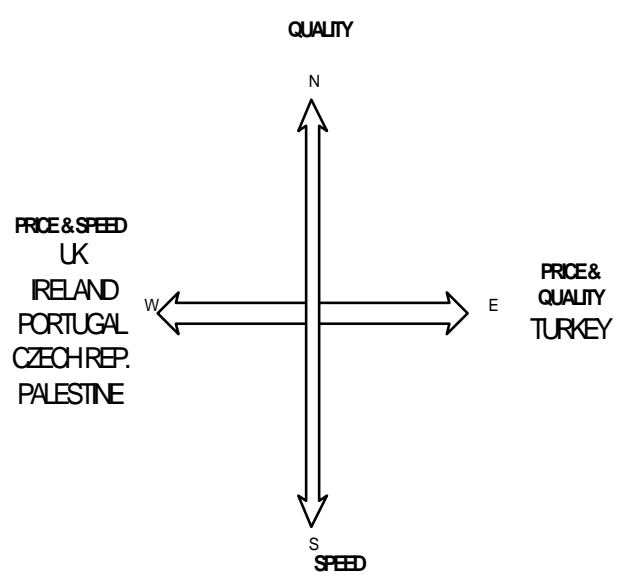

Fig. 11 Construction Competition

\section{ENVIRONMENTAL}

Figure 12 presents a view of the current development of environmental controls enacted by the various national governments. This component is closely linked to both the social and political components. A well developed impact and sustainability control regime would indicate that the PFI project is likely to encounter more detailed scrutiny than in countries with less developed controls. The cultural compass indicates a snapshot of the 'environmental awareness' which would determine additional project constraints that affect both the technological solution and also the financial cost of the project. The impact of environmental features is further described in De Lemos \& Eaton, (2004). 


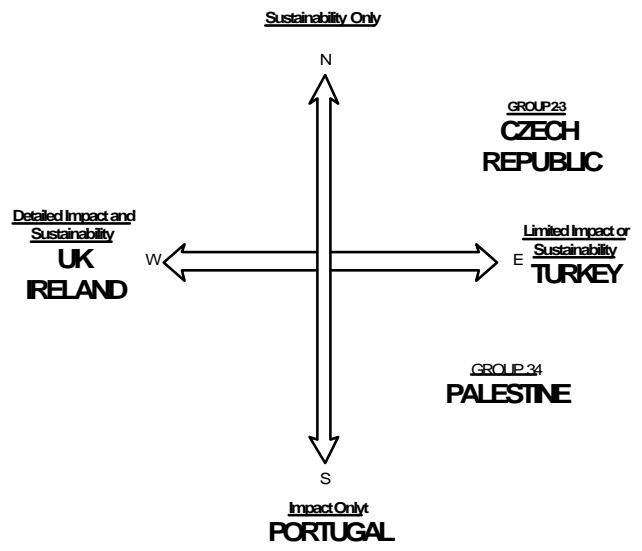

Fig. 12 Environmental Controls (Covering Conservation \& Heritage, Energy, Waste.

\section{POLITICAL.}

The Political component cannot be overlooked since it is only by Government will that any PFI project is commissioned. The NW quadrant would appear to be the most stable location for the successful delivery of PFI. Movements further SE would indicate a reduced favourability for PFI. The political stability of the Government interacts most significantly with the Economic and Technological components. Government stability would be a necessary precursor to the private sector lending money for the PFI project and also for the SPVs being prepared to risk significant bidding costs in preparing a project proposal.

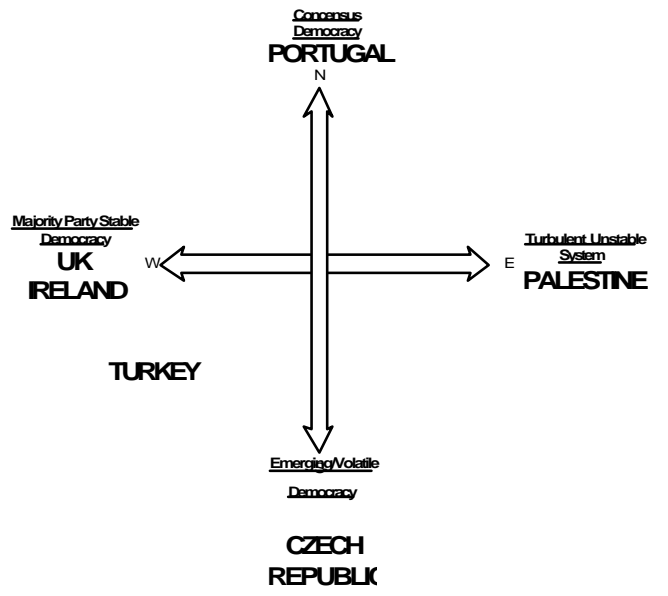

Fig. 13 Political System

\section{TECHNOLOGICAL}


Figure 14 presents technological differences in the approaches to project delivery. PFI is effectively achieved within the UK and Ireland using local contractors because of the historical prevalence of large main contractor companies. Portugal does not have the preponderance of large local contractors and PFI projects will have to create local consortia. There is also the possibility of creating 'smaller' sized PFI projects to accommodate the 'smaller' sized Portuguese and Palestinian contractor. Turkey and the Czech Republic have a few large contractors capable of sponsoring PFI, but their capacity is such that they will have limited scope to cover the anticipated demand. In such circumstances the creation of joint ventures between 'smaller' local companies and the large international contractor will be almost inevitable. This will be accompanied be the associated cultural and social difficulties indicated above. The Czech Republic had the additional experience of many major construction projects during the communist era.

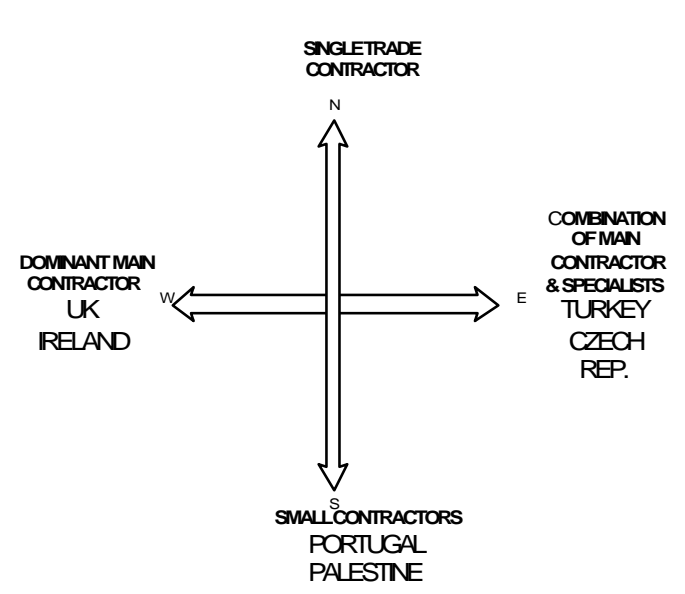

Fig. 14 Traditional Construction Co. Characteristics

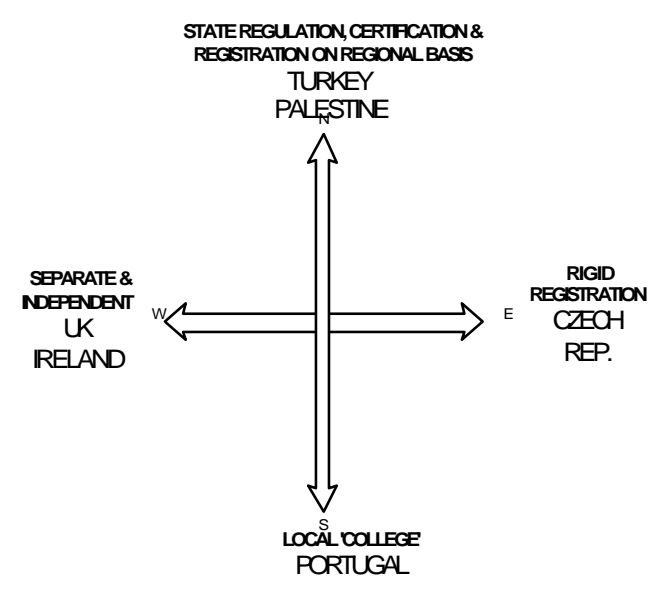

Fig. 15 Professional Controls

Figure 15 presents the comparison of 'consultants' control and regulation. Separate and independent professions within the UK and Ireland are replaced by state regulation in Palestine and Turkey and by local 'college' control in Portugal. The Czech approach is a combination of both the Turkish and Portuguese approach.

Figure 16 reflects the differences in the degree of construction regulation. The delivery of acceptable projects complying with national regulations will inevitably require different approaches based upon the local conditions. The Czech Republic had a CSN (Czechoslovakia Industrial Norm) adopted from the very extensive German DIN (Deutsche Industrie Norm) standard. This CSN was subject to many exceptions and exclusions; hence it became more flexible than the original DIN standard. 


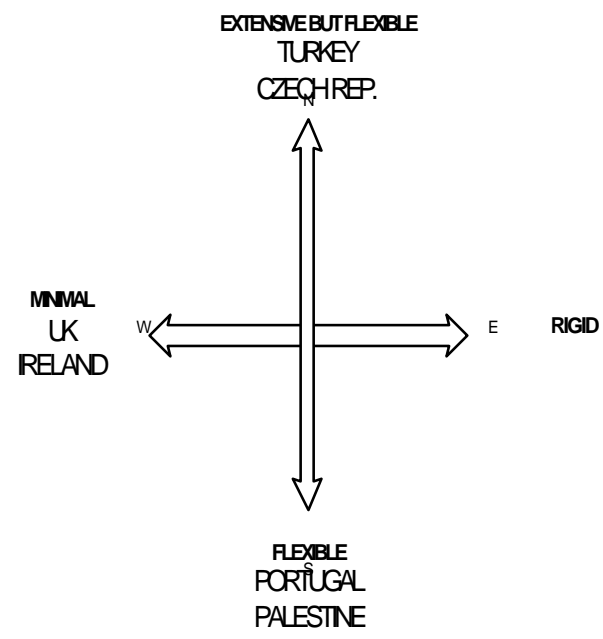

Fig. 16 Construction Controls

CROSS-CULTURAL VARIABILITY OF POSITIONS.

\section{THE UK}

Perfect 'component-by-component' compatibility is demonstrated by the UK. This is expected since the UK model is defined as the 'control' Western model. Figure 17 demonstrates this.

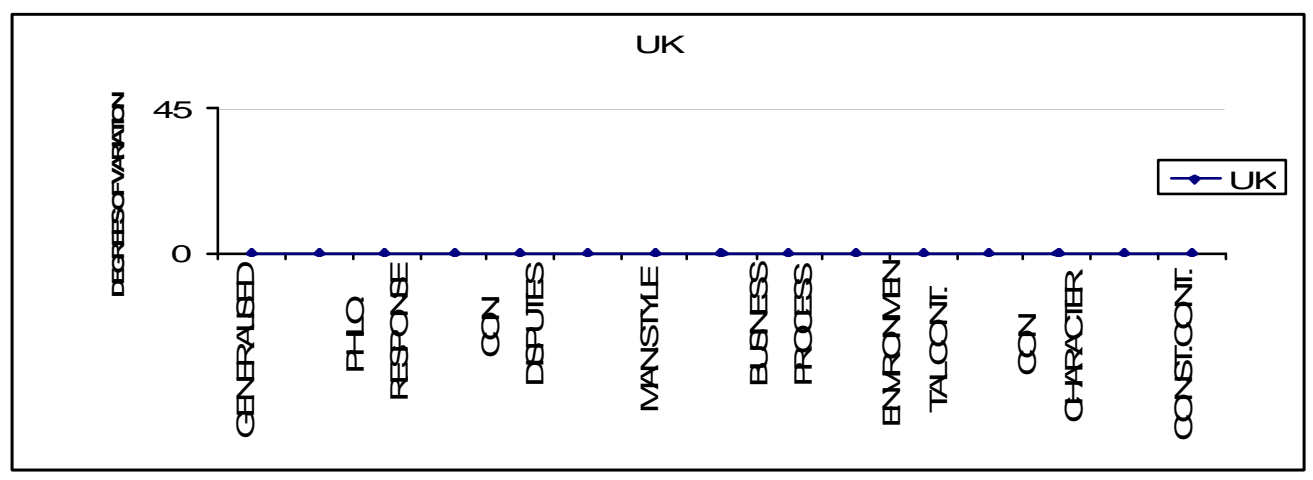

Figure 17 UK Cross-Cultural Compatibility

\section{THE REPUBLIC OF IRELAND}

The control position of Ireland was defined as 'Western'. Only component 8, the 'Business Orientation Characteristic' differs from the Western control model. Figure 18 indicates this. 
This would suggest that the 'Western control model' should be modified when applied in Ireland to accommodate a 'transforming business orientation' rather than the UK transactional orientation.

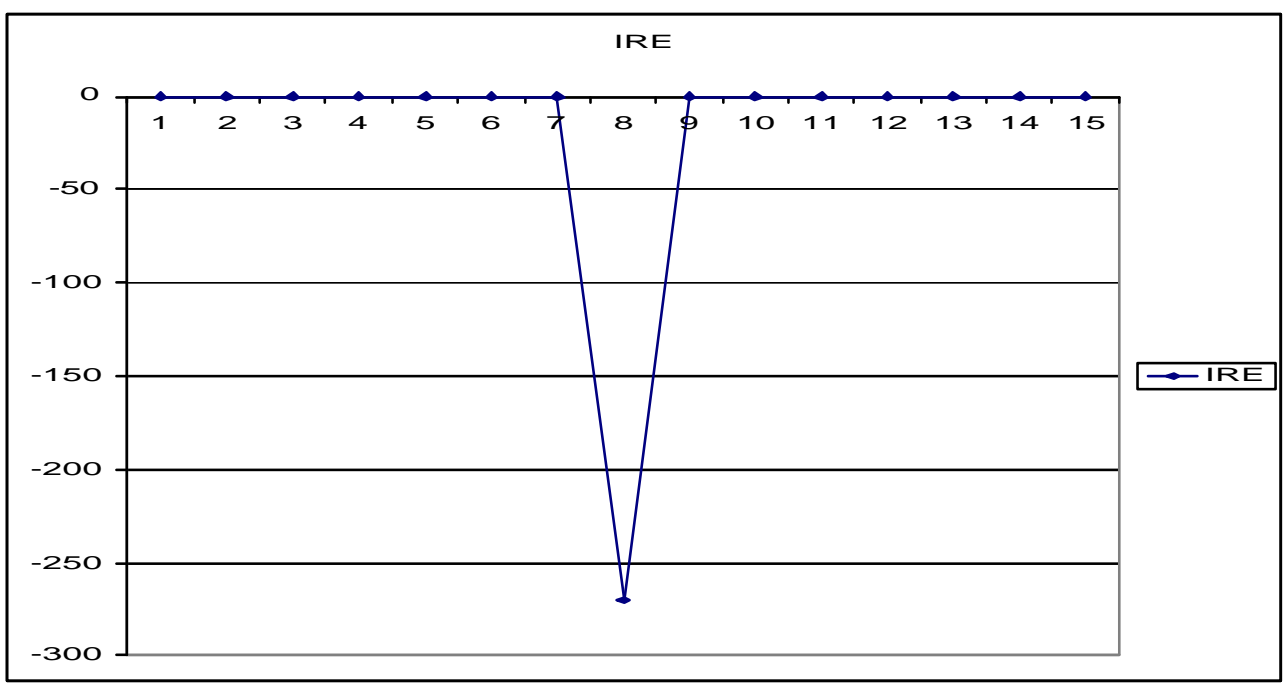

Figure 18 Ireland Cross-Cultural Compatibility

\section{PORTUGAL}

The control position of Portugal was defined as 'Southern'. Only components 10 and 12 differ from the standard 'Southern' control model. Component 10 is the Basis of Competition which is based upon price and speed rather than the defined speed only characteristic. Component 12 is the Political System characteristic which in Portugal is a consensus democracy rather than a volatile democracy. Figure 19 demonstrates this variation from the control.

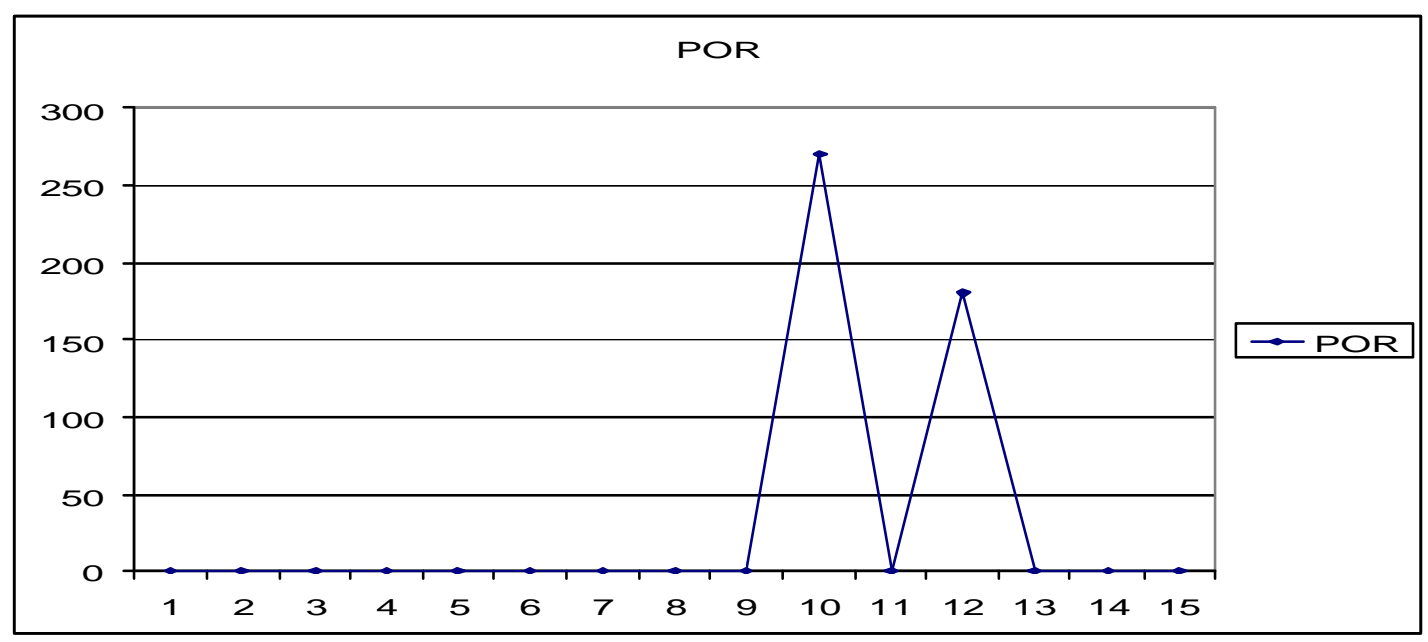

Figure 19 Portugal Cross-Cultural Compatibility

This suggests that the 'Southern' control model needs some adaptation for 'better fit' in Portugal.

\section{TURKEY}


The control position of Turkey was defined as 'Eastern'. Components 5, 8, 9, 12, 14 and 15 differ from the standard 'Eastern' control model. Component 5 is the Construction Disputes System, 8 is the Business Management System, 9 is the Business Process System, 12 is the Political system, 14 the Professional Controls of Construction and 15 the Degree of Construction Controls. Figure 20 demonstrates this variation.

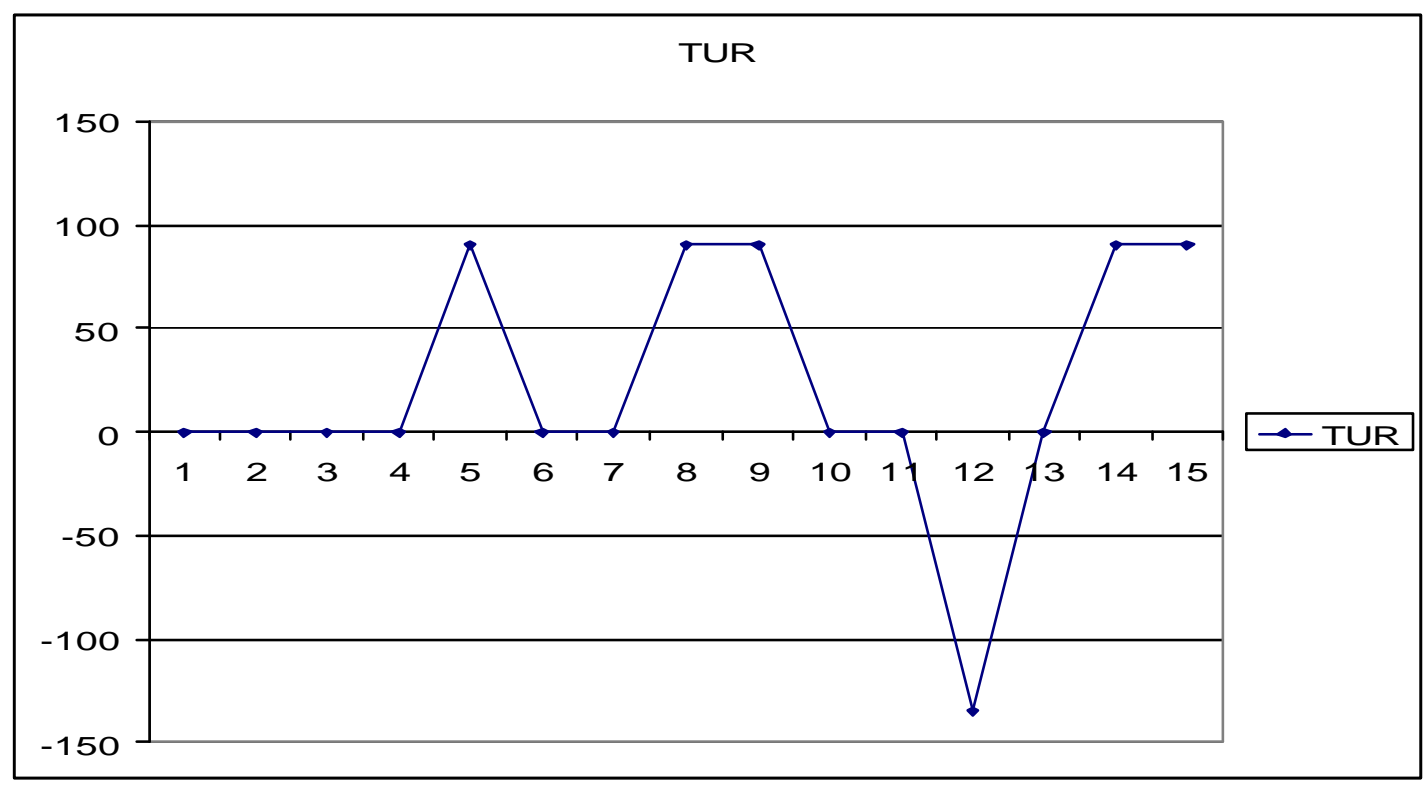

Figure 20 Turkey Cross-Cultural Compatibility

This would suggest that with so many variations from the 'Eastern' control position it would be better to construct a 'bespoke Turkish PFI system'.

\section{THE CZECH REPUBLIC}

The control position of the Czech Republic was defined as 'North-East'. This was already a compromise between the 'Northern' and 'Eastern' control positions. Even accepting this novel position many variations appear. Figure 21 demonstrates this. 


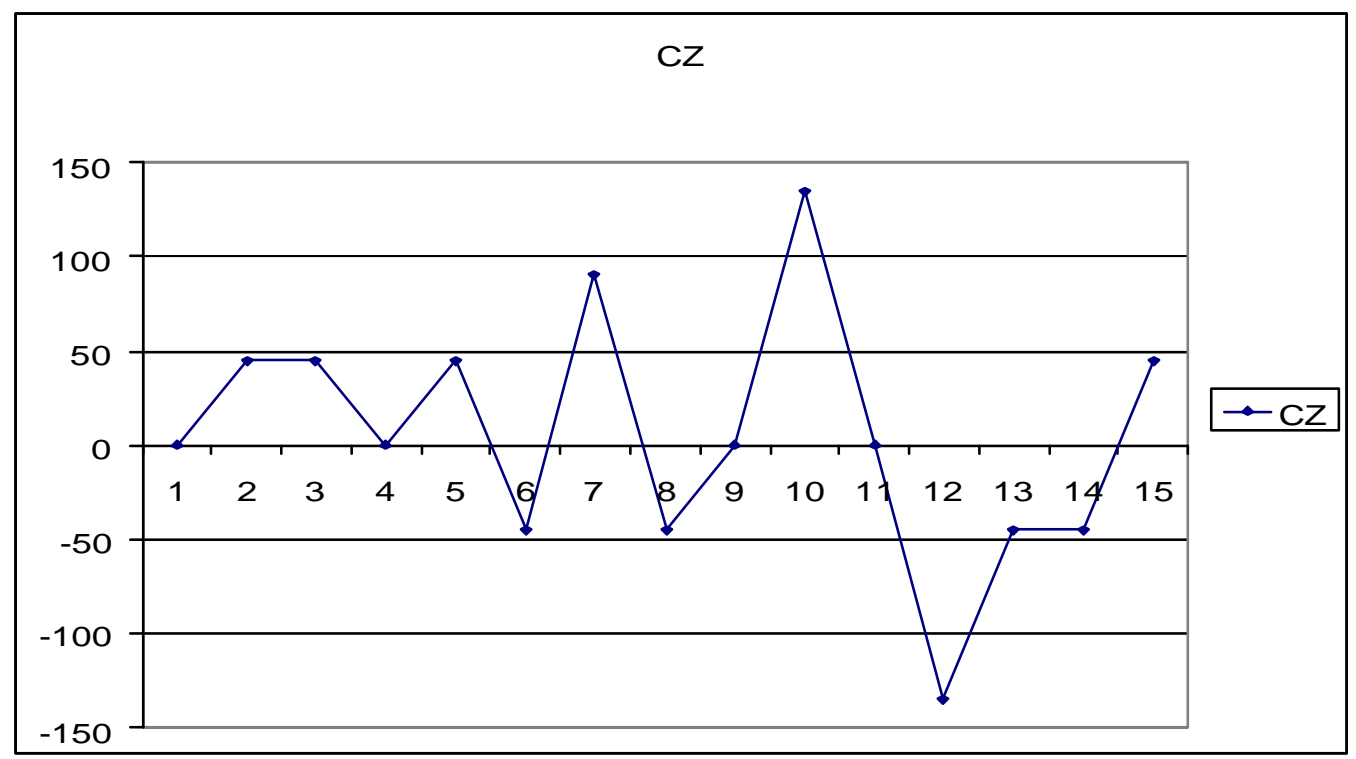

Figure 21 Czech Republic Cross-Cultural Compatibility

This would suggest that with so many variations from the 'North-Eastern' control position it would be better to construct a 'bespoke Czech PFI system'.

\section{PALESTINE}

The control position of Palestine (Gaza-West Bank) was defined as 'SouthEast'. This was already a compromise between the 'Southern' and 'Eastern' control positions. Even accepting this novel position many variations appear. Figure 22 demonstrates this.

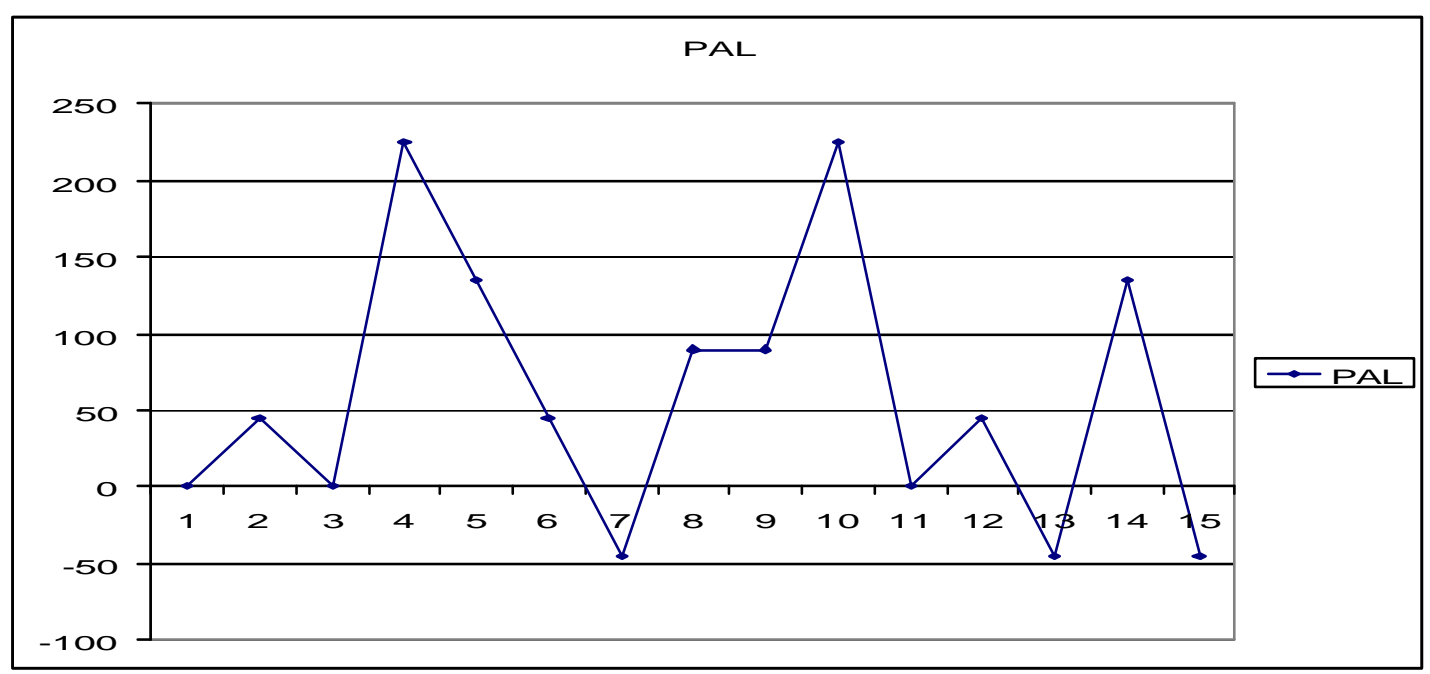

Figure 22 Palestine Cross-Cultural Compatibility

This would suggest that the defined control position is too volatile for a predetermined approach. It is suggested that the analysis indicates that a 'bespoke Palestinian PFI system' is required. 


\section{CONCLUSION}

A paper such as this inevitably contains many features that are approximated or generalised. Figure 23 presents a summary of the features identified within this research and presents a model that can be elaborated to contain many more nations. However the appreciation of cultural similarities and differences will have implications for the effective project delivery of future PFI/PPP projects.

Figure 23 presents a number of important features indicated by the hatched lines. The North/South hatched line indicates a distinction based upon the complexity or simplicity of the project documentation. To the West (i.e. UK and Ireland) the project documentation would be complicated and highly detailed whereas to the East (i.e. Turkey) the documentation would be less complicated with details being developed by the facilitation of the functional personnel. The Northwest/Southeast line differentiates between the Facilitator and the Interpreter. The UK, Ireland and Portugal would expect the interpretation of the detailed contractual documents, whilst in Palestine and Turkey the documents merely facilitate the delivery of the project objectives, much of the detail would be developed as the project proceeds. Thus a looser more personal relationship approach would be required. The Southwest/Northeast line differentiates between project deliverables. The UK and Ireland are delivering PPP/PFI projects to demonstrate national changes via psychological change in perceptions. Whilst in Portugal, Palestine and Turkey the project deliverables relate to improving the basic quality of life and demonstrate a radical humanist and approach. The Southeast/Northwest line indicates a similar theme based upon structural improvements in the UK, Ireland and Portugal, whilst the projects in Turkey reflect a demonstration of social progress. Palestine demonstrates features of both social progress and radical structuralism. The Czech Republic demonstrates many features of 'Simple-Structured-Formal-Technical Expertise'. It would be important to overlay the hatched line grid to the individual figures within the paper to represent an appropriate style of project development for particular aspects.

The movements around the compass for particular aspects are very noticeable. It makes the development of a 'generic' and 'internationalised' PFI approach almost impossible to achieve. This review indicates that the appropriate approach is that of a 'modified national' approach as represented in Figure 23.

The appreciation of cultural similarities and differences will have implications for effective project delivery of future PFI/PPP projects. PFI projects should be considered within the existing exogenous features of a nation. Merely implementing standardised PFI protocols without recognising these inherent differences will lead to project failures. This paper offers an approach that can be generalised for adoption by nations considering the introduction of $\mathrm{PFI}$ as a procurement process. 


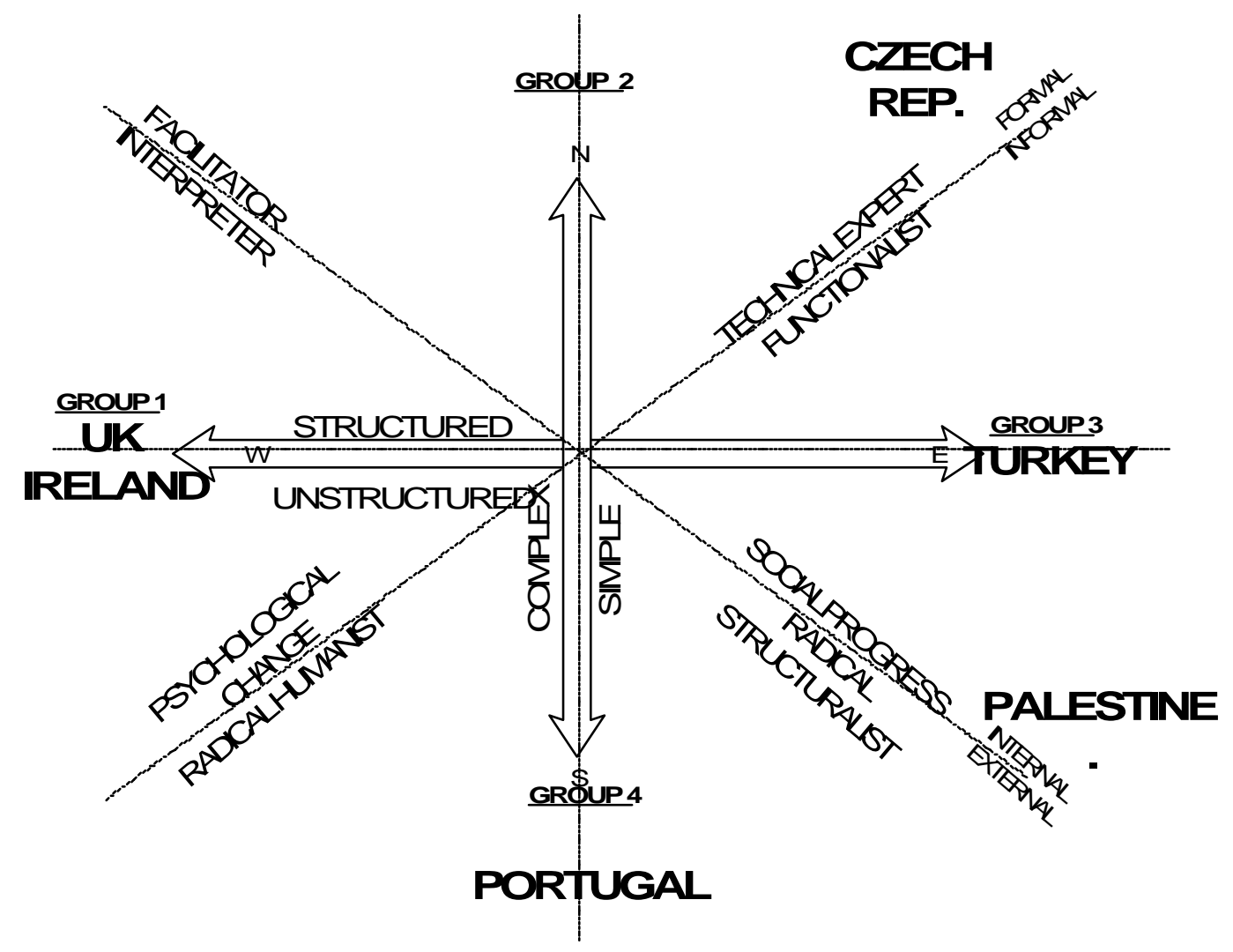

Fig. 23 Summary Cultural Compass

This paper represents a synoptic review of the work and a detailed analysis of the full implications cannot be presented within this paper. The model is not presented as a prescriptive model but as advisory to the modification of $\mathrm{PPP} / \mathrm{PFI}$ operational protocols. The concept can be generalised to consider any national economy considering the introduction of a PFI procurement system.

The research demonstrates that any nation embarking upon PFI should carefully consider the 'model of PFl' it wishes to adopt and not simply impose an alternative 'national' or 'Compass position' model.

\section{ACKNOWLEDGEMENTS}

The authors acknowledge the cooperation of many unnamed colleagues at the collaborating institutions for their assistance in determining 'national' locations for the parameters defined by the 'cultural compass' presented within this paper.

\section{REFERENCES}

ACCA Members Survey (2002), Do PFI Schemes Provide Value for Money? Report of The Association of Chartered Accountants, London. 
Akbiyikli, R. and Eaton, D. (2004) 'Private Finance Initiative (PFI): Unity in Diversity in Public Sector Service Provision.' Presentation in $4^{\text {th }}$ International Postgraduate Conference, $1^{\text {st }}$ and $2^{\text {nd }}$ April 2004, University of Salford.

Akintoye, A., Beck, M., Hardcastle, C., Chinyio, E. and Asenova, D. (2001) The Financial Structure of PFI Projects, ARCOM (Association of Researchers in Construction Management) Seventeenth Annual Conference, Sept. 5-7, University of Salford, Vol 1, pp361-369.

Andersen, A. and Enterprise LSE (2001), 'Value for Money Drivers in the Private Finance Initiative.' [cited 01 May 2004]. Available at: http://www.ogc.gov.uk/pfi/series 1/ andersen/7 tech contents.html

Aycan. Z., Kanungo, RN., Mendonca, M., Yu. K., Deller. J., Stahl. G., Kurshid. A., (2000) Impact of culture on human resource management practices: a 10country comparison.

De Lemos. T, Eaton D, (2003) Viable Roles for small construction companies (SMEs) in PFI. BEAR2003 CIB W89 International Conference on Building Education and Research 9-1 ${ }^{\text {th }}$ April. University of Salford.

De Lemos. T, Eaton D, (2004) Risk management in the Lusoponte concession - a case study of the two bridges in Lisbon, Portugal. International Journal of Project Management 22 (2004) 63-73

Eaton, D. (2000). A phenomenologically based contingent anatomy of competitive advantage within the construction industry, PhD Thesis, University of Salford: Salford.

Eaton, D. (2001a). A temporal typology for innovation within the construction industry, Construction Innovation, 1: 165-179.

Eaton. D (2001b) PFI Case Studies on UK Prisons and Portuguese Transport Sector. The Experience of PFI in the UK and Project Finance in Portugal, IST/University of Salford Workshop, Lisbon, $19^{\text {th }}$ January.

Eaton, D. (2004) 'Introduction to Risk Management'Presentation on April $27^{\text {th }}$ in the University of Sakarya, Turkey.

Eaton, D., (2004) 'Risk Transfer in PFI' Presentation on April $27^{\text {th }}$ in the University of Sakarya, Turkey.

Eaton, D. (2004) 'SLEEPT Factor Analysis for PFI Educational Projects' Presentation on April $28^{\text {th }}$ in the University of Sakarya, Turkey.

Eaton, D. (2004) 'Complex Adaptive Systems in The Built Environment' Presentation on April $28^{\text {th }}$ in the University of Sakarya, Turkey. 
Eaton, D., Akbiyikli, R., de Lemos. T., Gunnigan, L., Kutanis, RO., (2005) A Cross-Cultural Examination of PFI within the Republic of Ireland, Portugal, Turkey and the UK Utilising the SLEEPT Methodology. CIB W92 International Symposium on Procurement Systems. Las Vegas, NV. USA., February.

Eaton, D. \& Akbiyikli, R. (2005) PFI and the Delivery of Public Services. RICS Publications. www.rics.org/pfi

Hall, J. (1998), 'Private Opportunity, Public Benefit', Fiscal Studies, Vol.19, No.2, pp. 121-140.

Hall, M., Holt, R. and Purchase, D. (2003), 'Project sponsors under New Public Management: Lessons from the frontline.' International Journal of Project Management, 21, pp. 495-502.

Hampden Turner, C \& Trompenaars, F (1993) The Seven Cultures of Capitalism. Piatkus, London.

Henderson Global Investors (2003), 'What is PFI and Why is it An Attractive Investment?' London.

HM Treasury (1993), 'Breaking New Ground: Towards a New Partnership between the Public and Private Sector', London.

HM Treasury Taskforce (1997), 'Partnerships for Prosperity', November, London.

Hofstede, G. (1980) Cultures Consequences - International Differences in Work-related Values, (Abridged version) Sage, London.

Hofstede, G. (1994) Uncommon Sense about Organisations. Sage, London.

Hood, J. and McGarvey, N. (2002), 'Managing Risks of Public-Private Partnerships in Scottish Local Government'. Policy Studies, Vol. 23, No.1.

Lessem. R., Neubauer, F., (1994) European Management Systems: Towards unity out of cultural diversity. McGraw Hill.

Low, SP \& Shi, Y. (2001) Cultural influences on organizational processes in international projects: two case studies. Work Study. 50/7 276-285.

Pasa, SF. (2000) Leadership influence in a high power distance and collectivist culture. Leadership and Organisational Development Journal. 21/8 414-426.

NAO (2001), 'Building for the Future: The Management Procurement under the Private Finance Initiative'. 
Rhodes, R.A.W. (1997), 'Understanding Governance' Buckingham: Open University Press.

Rosenau, J.N. (1995), 'Governance in the twenty-first century'. Global Governance, 1(1), pp. 13-43.

Standard \& Poors (2004), 'PFI Projects Reshape the Credit Profile of Europe's Construction Companies', February.

Stoker, G. (1999), 'The moderniser's guide to local government', in G. Hassan and C. Warhurst (eds.). A Moderniser's Guide to Scotland - A Different Future. Edinburg/Glasgow: Centre for Scottish Public Policy/Big Issue in Scotland.

World Bank (1994), 'Governance: the World Bank's experience.' Washington, DC. World Bank. 